\title{
Atypical vitelliform macular dystrophy in a 5-generation family
}

\author{
HELEN MINTZ HITTNER, ${ }^{12}$ ROBERT E. FERRELL ${ }^{3}$ \\ ROBERT P. BORDA, ${ }^{4}$ AND JOHNNY JUSTICE JR ${ }^{1}$
}

From the ${ }^{1}$ Cullen Eye Institute, Baylor College of Medicine; ${ }^{2}$ Department of Pediatrics, Baylor College of Medicine; ${ }^{3}$ Center for Demographic and Population Genetics, Graduate School of Biomedical Sciences, University of Texas Health Science Center; and the ${ }^{4}$ Department of Neurology, Baylor College of Medicine, Houston, Texas, USA

\begin{abstract}
SUMMARY Five generations of a family with autosomal dominant atypical vitelliform macular dystrophy (A-VMD) were studied. This dystrophy is similar to autosomal dominant Best's vitelliform dystrophy (B-VMD) but clinically more closely resembles sporadic pseudovitelliform macular degeneration (P-VMD). Of the family members who were 14 years or older 43 (24 females and 19 males) of the 101 at risk (43\%) were affected. Vision varied from 20/20 to 20/200. Field defects and tritan colour defects were invariably present only when vision was $\leqslant 20 / 200$, but these defects were sometimes present when vision was good. The electrooculographic studies (LP/DT ratios) in this family were found to be normal or reduced and did not correlate with visual acuity. Minimal retinal findings consisted of macular or extramacular punctate yellow lesions or both in the retinal pigment epithelium, which were hypofluorescent by angiography, and retinal pigment epithelial defects in the temporal nerve fibre bundle, which were hyperfluorescent by angiography. Fluorescein angiographic changes were invariably present when retinal lesions were noted, and this was the most reliable test in identifying genotypically affected family members with minimal phenotypic expression.
\end{abstract}

Autosomal dominant retinal pigment epithelial (RPE) dystrophies include Best's vitelliform macular dystrophy (B-VMD), ${ }^{1}$ butterfly-shaped epithelial dystrophy (BED), ${ }^{2}$ foveomacular dystrophy (FMD), ${ }^{34}$ and drusen. ${ }^{5}$ Establishing a correct diagnosis in RPE dystrophies may be difficult in that B-VMD and BED may be a continuum. ${ }^{6}$ Further, the diagnosis may be confused because of sporadic conditions. Pseudovitelliform macular degeneration (PVMD) is similar morphologically to B-VMD, but is sporadic, shows a normal or slightly abnormal electro-oculogram, has a later age of onset, shorter period of evolution of the lesion, and a discrete atophic lesion as the end stage. ${ }^{7}$

This paper presents a large family with an autosomal dominant RPE dystrophy which is an atypical vitelliform macular dystrophy (A-VMD). There is complete penetrance but extreme variability of phenotypic expression, with different appearances to the primary lesions, multifocal lesions, and Correspondence to Dr Hittner, 7000 Fannin, Suite 2250, Houston, TX 77030-5570, USA. variable age of onset and rate of progression. The electro-oculogram is not always diminished in affected family members and cannot be used for genetic counselling. Fluorescein angiographic changes are invariably present when ophthalmoscopic lesions are identified, and are thus more valuable than electro-oculography in detecting genotypically affected family members with minimal phenotypic expression.

\section{Patients and methods}

Thirty-eight individuals in 4 generations of a single family were shown by examination (1981) to have A-VMD, and 6 more were ascertained by review of ophthalmological records. In addition 71 unaffected relatives were examined. Both affected and unaffected family members had the following examinations (1981): visual acuity best corrected, external examination, motility examination, examination by a hand-held slit-lamp, examination by direct and indirect ophthalmoscopy, and fundus photography. 


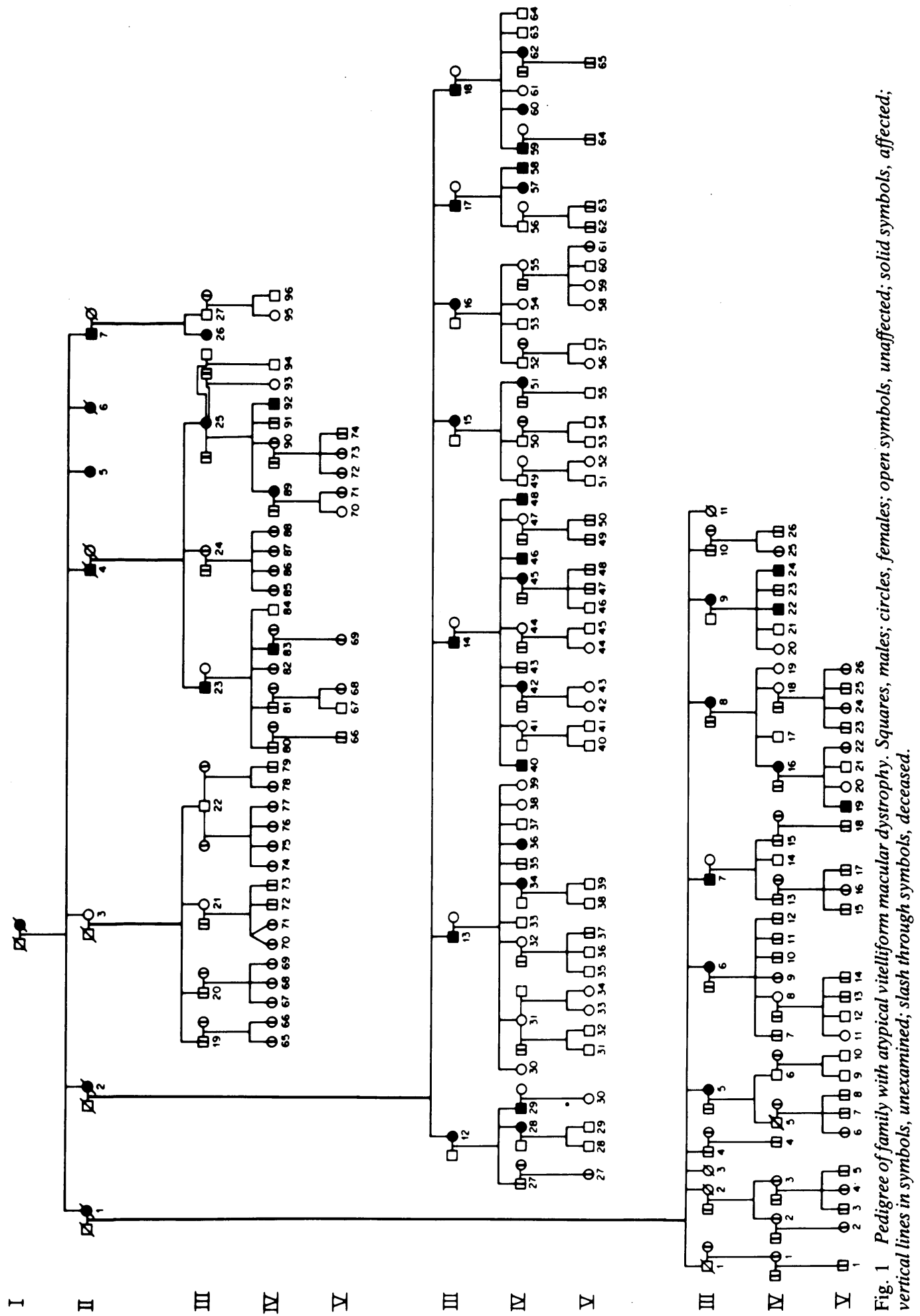


Table 1 Clinical data for 44 affected family members

\begin{tabular}{|c|c|c|c|c|c|c|c|}
\hline Patient & $D O B$ & $\operatorname{Sex}$ & $\begin{array}{l}\text { Visual acuity } \\
(O D-O S)\end{array}$ & Colour & $\begin{array}{l}E O G \\
(O D-O S)\end{array}$ & $\begin{array}{l}\text { Fundus } \\
\text { photographs }\end{array}$ & $\begin{array}{l}\text { Fluorescein } \\
\text { angiograms }\end{array}$ \\
\hline$I^{*}$ & 14 Jul 1870 & $\mathrm{~F}$ & [[poor vision]] & & & & \\
\hline $\mathbf{I I}_{1}$ & 05 Feb 1893 & $\mathrm{~F}$ & {$[20 / 80 \quad 20 / 200]$} & & & $3 A$ 3B 3C & $\dagger$ \\
\hline $\mathrm{II}_{2}$ & 30 Nov 1895 & $\mathrm{~F}$ & [[poor vision]] & & & & \\
\hline $\mathrm{II}_{4}$ & 23 Mar 1902 & $\mathbf{M}$ & {$\left[\begin{array}{ll}20 / 40 & 20 / 60\end{array}\right]$} & & $2 \cdot 2 / 2 \cdot 2$ & $1 \mathrm{~A} 2 \mathrm{~B} 0 \mathrm{C}$ & $\dagger$ \\
\hline $\mathrm{II}_{5}$ & 09 Aug 1909 & $\mathbf{F}$ & $20 / 20020 / 200$ & $\ddagger$ & $1 \cdot 6 \| / 1 \cdot 7$ & 3A 3B 1C & $\dagger$ \\
\hline $\mathrm{II}_{6}$ & 14 Nov 1913 & $\mathrm{~F}$ & {$[20 / 25 \quad 20 / 30]$} & & $2 \cdot 2 / 2 \cdot 0$ & $2 \mathrm{~A} 3 \mathrm{~B} 2 \mathrm{C}$ & $\dagger$ \\
\hline $\mathrm{II}_{7}$ & 22 Jun 1915 & $\mathbf{M}$ & $20 / 30 \quad 20 / 30$ & & & $1 \mathrm{~A} 2 \mathrm{~B} 3 \mathrm{C}$ & $\dagger$ \\
\hline $\mathrm{III}_{5}$ & 14 Sept 1917 & F & $20 / 10020 / 200$ & & & $2 \mathrm{~A} 3 \mathrm{~B} 3 \mathrm{C}$ & $\S$ \\
\hline III $_{6}$ & 08 Apr 1920 & $\mathbf{F}$ & $20 / 20 \quad 20 / 20$ & & & $1 \mathrm{~A} 2 \mathrm{~B} 0 \mathrm{C}$ & $\S$ \\
\hline $\mathrm{III}_{7}$ & $14 \operatorname{Dec} 1926$ & $\mathbf{M}$ & $20 / 30 \quad 20 / 30$ & & $2 \cdot 4 / 2 \cdot 8$ & 2A 2B 3C $\|$ & $\dagger$ \\
\hline $\mathrm{III}_{8}$ & 15 Mar 1929 & $\mathrm{~F}$ & $20 / 20 \quad 20 / 20$ & & & $1 \mathrm{~A} 3 \mathrm{~B} 0 \mathrm{C}$ & $\S$ \\
\hline III $_{9}{ }^{*}$ & 07 Mar 1930 & $\mathrm{~F}$ & $20 / 30 \quad 20 / 20$ & $\ddagger$ & & $1 \mathrm{~A} 2 \mathrm{~B} 0 \mathrm{C}$ & $\dagger$ \\
\hline $\mathrm{III}_{12}$ & 18 Nov 1916 & $\mathrm{~F}$ & $20 / 30 \quad 20 / 200$ & & $3 \cdot 2 \| / 2 \cdot 6$ & $3 \mathrm{~A} \| 2 \mathrm{~B} 0 \mathrm{C}$ & + \\
\hline $\mathrm{III}_{13}$ & 18 Apr 1918 & $\mathbf{M}$ & $20 / 20 \quad 20 / 100$ & & & $2 \mathrm{~A} 2 \mathrm{~B} 2 \mathrm{C}$ & $\S$ \\
\hline $\mathrm{III}_{14}{ }^{*}$ & 15 Jan 1920 & $\mathbf{M}$ & $20 / 40 \quad 20 / 30$ & $\ddagger$ & & $1 \mathrm{~A} \| 1 \mathrm{~B} 0 \mathrm{C}$ & $\dagger$ \\
\hline III $_{15}^{*}$ & 08 Aug 1922 & F & $20 / 30 \quad 20 / 40$ & & & $1 \mathrm{~A} 2 \mathrm{~B} 1 \mathrm{C}$ & + \\
\hline III $_{16}$ & 12 Dec 1924 & $\mathbf{F}$ & $20 / 30 \quad 20 / 30$ & $\ddagger \|$ & & $1 \mathrm{~A} 1 \mathrm{~B} 1 \mathrm{C} \|$ & + \\
\hline $\mathrm{III}_{17}{ }^{*}$ & 29 Jun 1926 & $\mathbf{M}$ & $20 / 20020 / 200$ & $\neq \|$ & $2 \cdot 4 \| / 2 \cdot 3$ & $3 \mathrm{~A} 1 \mathrm{~B} 1 \mathrm{C}$ & $\dagger$ \\
\hline $\mathrm{III}_{18}{ }^{*}$ & 31 Jul 1928 & $\mathbf{M}$ & $20 / 20 \quad 20 / 30$ & $\ddagger$ & & $1 \mathrm{~A} \| 1 \mathrm{~B} 0 \mathrm{C}$ & $\dagger$ \\
\hline $\mathrm{III}_{23}$ & 06 Jun 1927 & $\mathbf{M}$ & $20 / 20020 / 200$ & & $1 \cdot 6 / 1 \cdot 5$ & $3 \mathrm{~A} 2 \mathrm{~B} 1 \mathrm{C}$ & + \\
\hline $\mathrm{III}_{25}$ & 07 Sept 1932 & $F$ & $20 / 20 \quad 20 / 60$ & & & $1 \mathrm{~A} 2 \mathrm{~B} 0 \mathrm{C}$ & + \\
\hline $\mathrm{III}_{26}{ }^{* *}$ & 30 Sept 1949 & $\mathrm{~F}$ & $20 / 20 \quad 20 / 20$ & + & & $1 \mathrm{~A} 1 \mathrm{~B} 2 \mathrm{C}$ & $\dagger$ \\
\hline $\mathrm{IV}_{16}$ & 06 Jan 1948 & $\mathbf{F}$ & $20 / 20 \quad 20 / 20$ & & & $1 \mathrm{~A} 2 \mathrm{~B} 0 \mathrm{C}$ & $\S$ \\
\hline $\mathrm{IV}_{22}{ }^{* *}$ & $14 \operatorname{Dec} 1952$ & $\mathbf{M}$ & $20 / 20 \quad 20 / 20$ & $\dagger$ & & $1 \mathrm{~A} 1 \mathrm{~B} 1 \mathrm{C}$ & $\dagger$ \\
\hline $\mathrm{IV}_{24}{ }^{* *}$ & 28 Jun 1962 & $\mathbf{M}$ & $20 / 20 \quad 20 / 20$ & $\dagger$ & & $1 \mathrm{~A} 1 \mathrm{~B} 0 \mathrm{C}$ & $\dagger$ \\
\hline $\mathrm{IV}_{28}$ & 28 Dec 1943 & $\mathbf{F}$ & $20 / 30 \quad 20 / 70$ & & & $1 \mathrm{~A} 2 \mathrm{~B} 0 \mathrm{C}$ & $\S$ \\
\hline$I_{29}$ & $18 \mathrm{Jan} 1946$ & $\mathbf{M}$ & $20 / 20020 / 100$ & & $2 \cdot 2 / 2 \cdot 2$ & $2 \mathrm{~A} \| 2 \mathrm{~B} 0 \mathrm{C}$ & + \\
\hline $\mathrm{IV}_{34}{ }^{*}$ & 01 Jun 1952 & $\mathbf{F}$ & $20 / 20 \quad 20 / 20$ & & & $0 A 1 B 1 C$ & + \\
\hline $\mathrm{IV}_{36}{ }^{* *}$ & 16 Jan 1957 & $\mathbf{F}$ & $20 / 20 \quad 20 / 20$ & & & $0 A 1 B 1 C$ & $\dagger$ \\
\hline $\mathrm{IV}_{40}{ }^{* *}$ & 14 Sept 1945 & $\mathbf{M}$ & $20 / 20 \quad 20 / 20$ & & & $1 \mathrm{~A} 1 \mathrm{~B} 0 \mathrm{C}$ & $\dagger$ \\
\hline $\mathrm{IV}_{42}$ & 08 Jan 1953 & $\mathbf{F}$ & $20 / 20 \quad 20 / 20$ & & & $1 \mathrm{~A} 2 \mathrm{~B} 0 \mathrm{C}$ & + \\
\hline $\mathrm{IV}_{45}{ }^{* *}$ & 08 Nov 1957 & $\mathbf{F}$ & $20 / 20 \quad 20 / 20$ & & & 0A 1B 2C\| & $\dagger$ \\
\hline$I_{46}$ & 13 Nov 1958 & $\mathbf{M}$ & $20 / 20 \quad 20 / 20$ & & & $1 \mathrm{~A} 1 \mathrm{~B} 0 \mathrm{C}$ & + \\
\hline $\mathrm{IV}_{48}$ & 24 Jul 1961 & $\mathbf{M}$ & $20 / 20 \quad 20 / 20$ & & & $0 A$ 2B 1C & $\dagger$ \\
\hline$I V_{s 1}$ & 08 Aug 1951 & $F$ & $20 / 30 \quad 20 / 25$ & & & $1 \mathrm{~A} 1 \mathrm{~B} 0 \mathrm{C}$ & + \\
\hline $\mathrm{IV}_{57}{ }^{* *}$ & 26 Aug 1962 & $\mathrm{~F}$ & $20 / 20 \quad 20 / 20$ & $\dagger$ & $2 \cdot 7 / 2 \cdot 5$ & $1 \mathrm{~A} 2 \mathrm{~B} 0 \mathrm{C}$ & + \\
\hline $\mathrm{IV}_{58}{ }^{* *}$ & 03 Jun 1965 & $\mathbf{M}$ & $20 / 20 \quad 20 / 20$ & & & $1 \mathrm{~A} 2 \mathrm{~B} 0 \mathrm{C}$ & $\dagger$ \\
\hline $\mathrm{IV}_{59}{ }^{*}$ & 13 Dec 1951 & $\mathbf{M}$ & $20 / 20 \quad 20 / 20$ & & & $1 \mathrm{~A} 2 \mathrm{~B} 1 \mathrm{C}$ & $\dagger$ \\
\hline $\mathrm{IV}_{60}{ }^{* *}$ & 05 Jul 1953 & $\mathbf{F}$ & $20 / 20 \quad 20 / 20$ & & & 0A 1B 1C & $\dagger$ \\
\hline $\mathrm{IV}_{62}{ }^{*}$ & 26 Feb 1958 & $\mathbf{F}$ & $20 / 20 \quad 20 / 20$ & - & & $1 \mathrm{~A} 1 \mathrm{~B} 0 \mathrm{C}$ & $\dagger$ \\
\hline $\mathrm{IV}_{83}$ & 24 May 1953 & $\mathbf{M}$ & $20 / 20 \quad 20 / 20$ & - & & $1 \mathrm{~A} 1 \mathrm{~B} 1 \mathrm{C} \|$ & $\dagger$ \\
\hline$I_{89}$ & $14 \operatorname{Dec} 1953$ & $\mathrm{~F}$ & $20 / 20 \quad 20 / 20$ & & & $1 \mathrm{~A} 2 \mathrm{~B} 0 \mathrm{C}$ & $\S$ \\
\hline $\mathrm{IV}_{92}$ & 22 Nov 1956 & $\mathbf{M}$ & $20 / 25 \quad 20 / 25$ & & $1 \cdot 6 \| / 2 \cdot 1$ & $2 \mathrm{~A} 2 \mathrm{~B} 1 \mathrm{C}$ & $\dagger$ \\
\hline $\mathrm{V}_{19}{ }^{* *}$ & 26 May 1967 & $\mathbf{M}$ & $20 / 20 \quad 20 / 20$ & & & $0 A$ 2B 1C & $\S$ \\
\hline
\end{tabular}

$\mathrm{DOB}=$ Date of birth. $\mathrm{EOG}=$ Electrooculogram (light peak to dark trough ratio). OD=Right eye. OS=Left eye. ${ }^{*}=\mathrm{GPT} 1 \mathrm{Type} 2-1$, i.e. doubly heterozygous, with children. ${ }^{* *}=$ GPT1 Type $2-1$, i.e. doubly heterozygous, without children. $M=$ Male. $F=$ Female. [[ ]]=Died prior to 1974 studies. [ ]=Died prior to 1981 studies. $\dagger=$ Normal. $\ddagger=$ Abnormal. $\S=$ Not performed. $0=$ Normal. $1=$ Minimal. $2=$ Moderate. $3=$ Severe. $A=$ Macular. $B=$ Peripapillary. $C=$ Peripheral. Fig. 1 shows the position of each patient in the pedigree. $\|$ Marks information given in Figs. 2-7.

Twelve affected patients had central visual field testing, 10 affected patients had 100 -hue colour testing, 10 affected patients had electro-oculograms (1974), ${ }^{8}$ and 34 affected and 16 unaffected patients had fundus fluorescein angiography (1974 and/or 1981).

\section{Results}

The family pedigree (Fig. 1) showed the segregation of A-VMD to be consistent with an autosomal dominant inheritance pattern with complete penetrance and 7 instances of male to male transmission. Of the 44 affected members 25 were females and 19 were males. Slightly fewer than $50 \%$ of the family members at risk who were older than 14 years were known to be affected $(43 \%$; 43 of 101). Family members were designated as affected on the basis of moderate or severe retinal lesions seen ophthalmoscopically with or without fluorescein angiography, or on the basis of minimal retinal lesions 

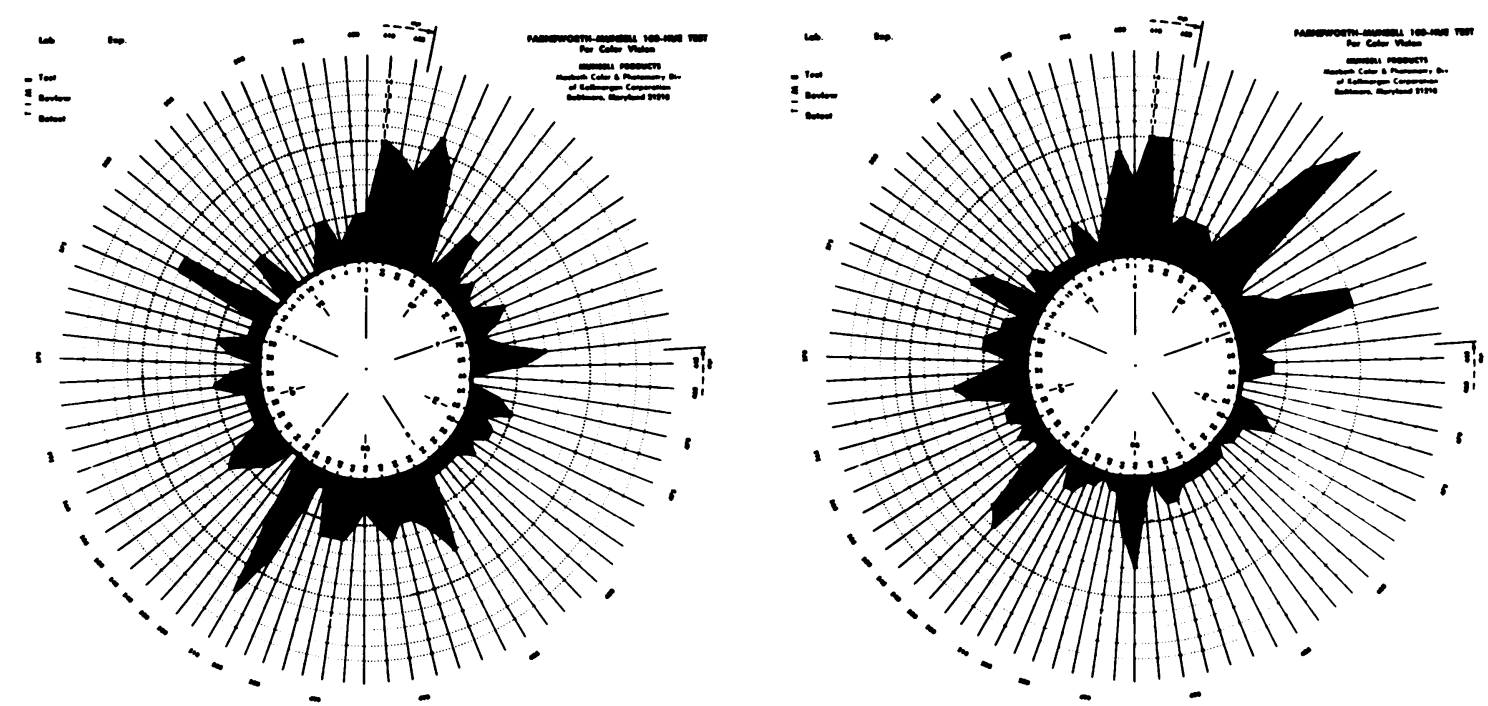

Fig. 2 Colour abnormalities in 2 affected family members. Left, patient III ${ }_{16}$ (age 61 years; visual acuity OU: 20/30). Right, patient $I I I_{17}$ (age 54 years; visual acuity OU: 20/200).

seen or suspected ophthalmoscopically and substantiated by fluorescein angiography (See Table 1). All family members except 3 in generation IV $\left(\mathrm{IV}_{94-96}\right)$ were older than 14 years, while only 3 family members in generation $\mathrm{V}\left(\mathrm{V}_{19-21}\right)$ were at least 14 years of age. $V$ isual acuities in the affected family members ranged from $20 / 20$ to $20 / 200$, with only 6 family members having a visual acuity of 20/200 or less in one or both eyes $\left(\mathrm{II}_{5}, \mathrm{III}_{5}, \mathrm{III}_{12}, \mathrm{III}_{17}, \mathrm{III}_{23}\right.$, and $\left.\mathrm{IV}_{29}\right)$.

Amsler grid visual fields were performed on 12 affected family members. A central visual field defect was noted only in those family members whose visual acuity was markedly reduced.

A complete or partial tritan colour defect was found in 6 of 10 of the affected family members tested. There was no correlation between visual acuity and the colour defect (Fig. 2); however, in 2 family members whose visual acuity was $20 / 200$ or less the tritan colour defect was present.

Electro-oculograms were performed in 1974 on 10 affected family members. The electro-oculogram was abnormal (Fig. 3, top) in only 3 affected family members (ages 16 to 65 years at the time of examination). Visual acuities in these 3 family members ranged from $20 / 25$ to $20 / 200$. In the 7 affected family members (ages 12-72 years at the time of examination) with normal electro-oculograms (Fig. 3, bottom), visual acuities ranged from 20/20 to 20/200. Thus decreased visual acuity did not correlate with an abnormal electro-oculogram.

Fig. 3 Electro-oculograms of 4 affected family members. Top left, patient $I V_{92}$ (age 16 years; visual acuity $O D: 20 / 25)$. LP/DT ratio 1.6. Top right, patient $I_{5}$ (age 65 years; visual acuity $O D: 20 / 200$ ). LP/DT ratio $1 \cdot 6$. Bottom left, patient III ${ }_{12}$ (age 58 years; visual acuity $O D: 20 / 30)$. LPIDT ratio 3.2. Bottom right, patient $\mathrm{III}_{17}$ (age 47 years; visual acuity $O D: 20 / 200)$. $L P / D T$ ratio $2 \cdot 4$. Normal $L P / D T$ ratio $1 \cdot 7-4 \cdot 0$. Each dot represents the average of 7 to 10 ocular rotations at a rate of one rotation per second. Shaded area =dark adapted testing. Unshaded area $=$ light adapted testing.

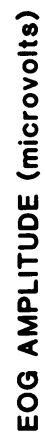

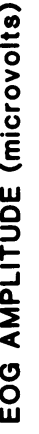
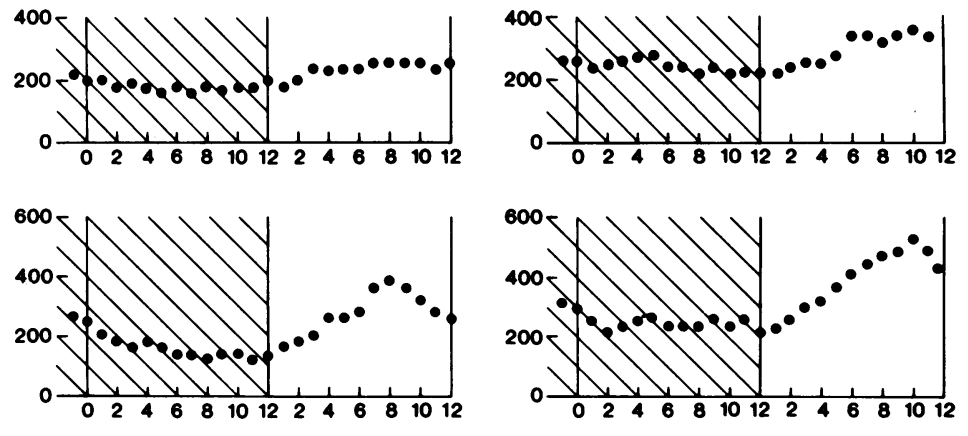

TIME (minutes) 

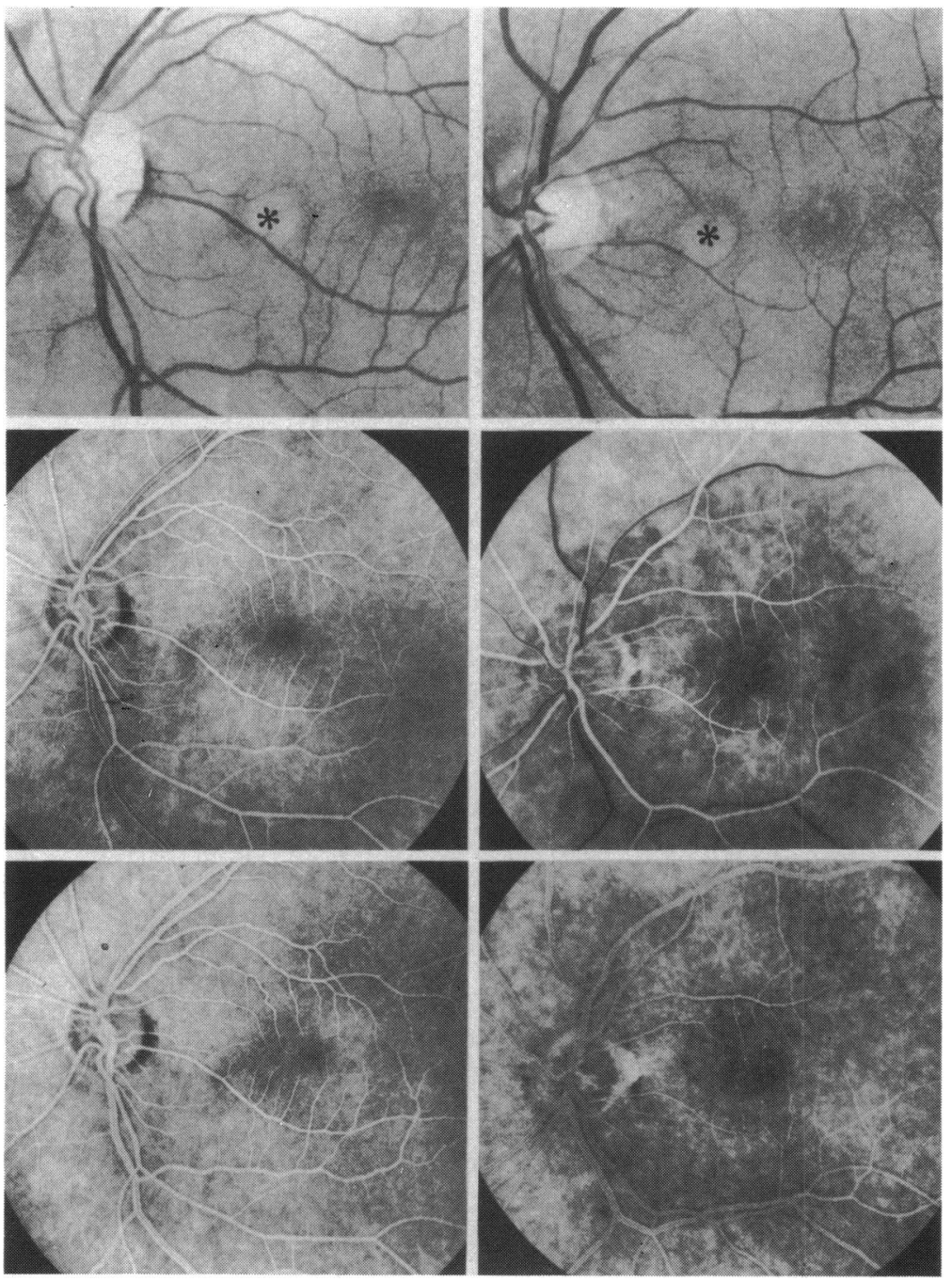

Fig. 4 Mild central retinal abnormalities in 2 affected family members demonstrated by fundus photography and fluorescein angiography. Left, patient III 18 (age 53 years; visual acuity 20/20). The macular region of the left eye appears normal ophthalmoscopically and there is only a slight defect in the nerve fibre bundle temporally (top). However, there are foveal fluorescence and peripapillary retinal pigment epithelial defects angiographically (middle and bottom). Right, patient III $I_{14}$ (age 61 years; visual acuity 20/30). The macular region of the left eye has a slight yellow appearance ophthalmoscopically and there is a defect in the nerve fibre bundle temporally (top), and there are foveal fluorescence and peripapillary retinal pigment epithelial defects angiographically (middle and bottom). (Asterisks mark camera artefact.)
Fundus photographs and fluorescein angiograms were used to document the variable phenotypic expression of the dystrophy of the retinal pigment epithelium. The multifocal nature of this dystrophy with both central and peripheral lesions is shown in minimal (Figs. 4 and 5), moderate (Fig. 6), and severe (Fig. 7) forms.

Minimal changes consisted of small yellow lesions in the macular and/or peripheral retina and small defects in the temporal peripapillary region. Moderate changes included elevated ('fried egg') yellow lesions in the macula or peripheral retina, and defects (usually $90^{\circ}-180^{\circ}$ ) in the temporal peripapillary region. In minimal and moderate cases the yellow lesions were hypofluorescent in early but hyperfluorescent in late fluorescein angiograms, while the peripapillary lesions were uniformly hyperfluorescent. Severe changes included advanced vitelliform macular or peripheral lesions which had depigmented centres and pigment clumping around the edges without hypertrophic scarring, and large (usually $360^{\circ}$ ) retinal pigment epithelial defects in the peripapillary region. In these cases the fluorescein angiograms showed the defects as hyperfluorescent areas from early to late. Some patients had minimal central lesions and severe peripheral lesions simultaneously (and vice versa). In some cases retinal lesions advanced from minimal to moderate or from moderate to severe from 1974 to 1981 , and in 2 cases visual acuity decreased from normal to legal blindness in one eye during this period ( $\mathrm{III}_{12}$ and $\mathrm{IV}_{\mathbf{2 9}}$ ). 
Fig. 5 Mild peripheral retinal abnormalities in 2 affected family members demonstrated by fundus photography and fluorescein angiography. Left, patient $I V_{83}$ (age 28 years; visual acuity 20/20). A small yellow dot (arrow) is apparent in the right eye ophthalmoscopically (top), less apparent (arrow) by early angiography (middle), but well demonstrated (arrow) by late angiography (bottom). Right, patient III $I_{16}$ (age 57 years; visual acuity 20/30). A few small yellow lesions (arrow) are apparent in the right eye ophthalmoscopically (top), hypofluorescent (arrow) by early angiography (middle), but hyperfluorescent (arrow) by late angiography (bottom). (Asterisks mark camera artefact.)
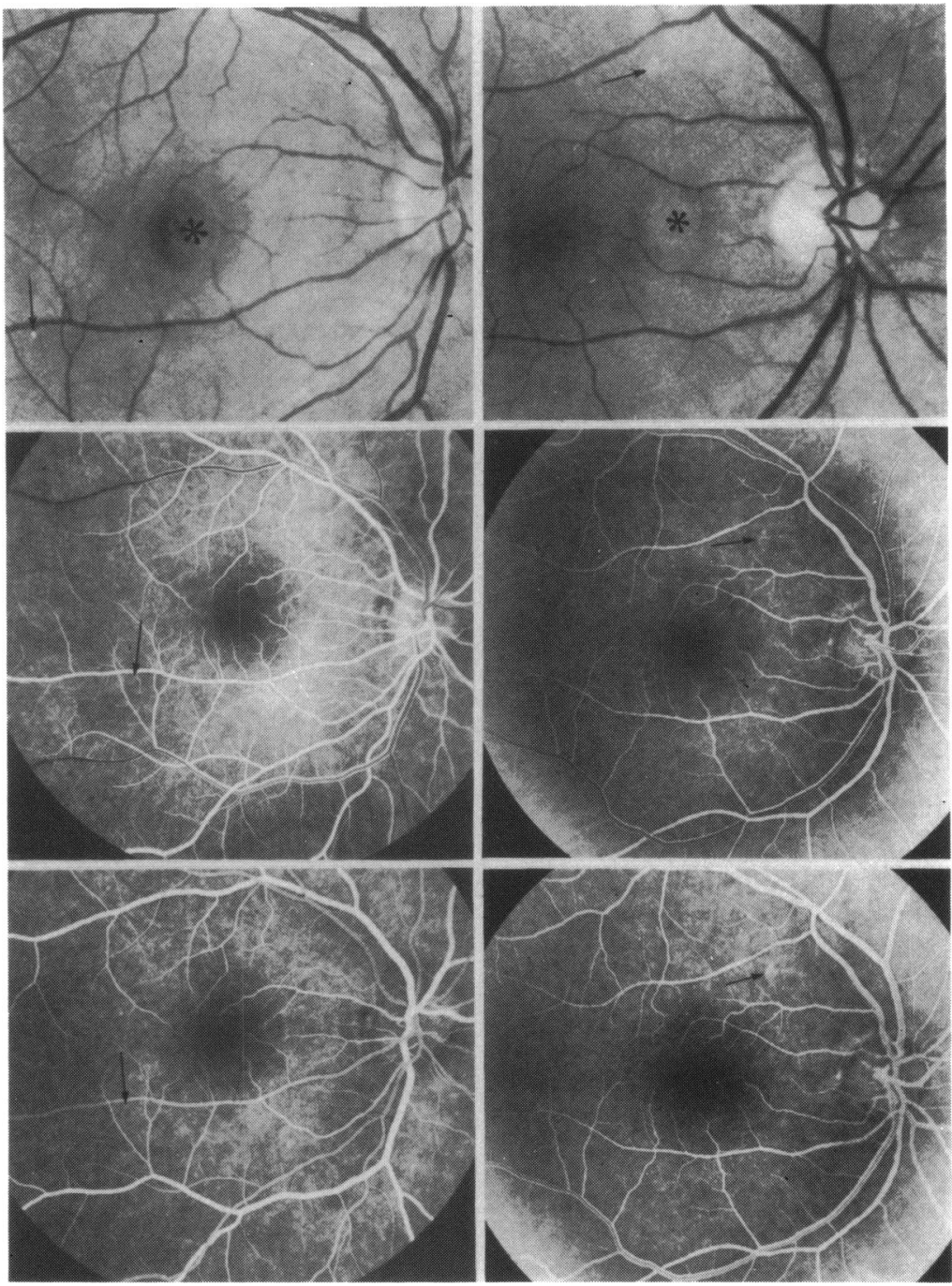

\section{Discussion}

The ophthalmoscopic appearance of B-VMD may be polymorphous, ${ }^{10}$ multifocal lesions may occur, ${ }^{11}$ and the age of onset and rate of progression of the dystrophy may vary considerably even within single families. In B-VMD fundus lesions have been reported at birth, but they are more typically discovered between ages 3 and 15 years. There have been good reports that the lesions can develop late in life, and that the age of clinical onset may vary considerably within a single family. Electrooculography, ${ }^{12-14}$ fluorescein angiography, ${ }^{15-17}$ and pathological studies have all localised the pathology in B-VMD to the retinal pigment epithelium. ${ }^{18}$ Recent reviews ${ }^{1-21}$ have emphasised that the main criteria for the diagnosis of B-VMD are family history (autosomal dominant pedigree), visual loss in advanced cases (with high variability in appearance of the lesions), and a diminished electro-oculogram.

In contrast P-VMD is generally sporadic, except in 2 instances of apparent autosomal dominance in two generations. ${ }^{34}$ The lesions are usually smaller than those of B-VMD, the electro-oculogram is normal or slightly decreased, the onset is later in life, with a slower progression, and an end stage which is atrophic (not hypertrophic). ${ }^{72-27}$

This family with A-VMD demonstrates extreme variability of expression, including differences in appearance and location of the lesions, and in their variable age of clinical onset and progression. Inconsistent abnormalities were found with field and 

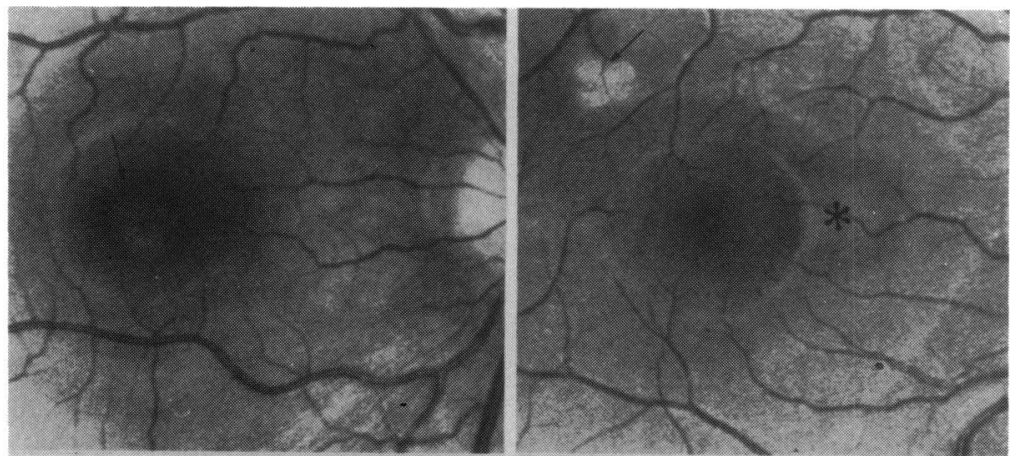

Fig. 6 Moderate central and peripheral retinal abnormalities in 2 affected family members demonstrated by fundus
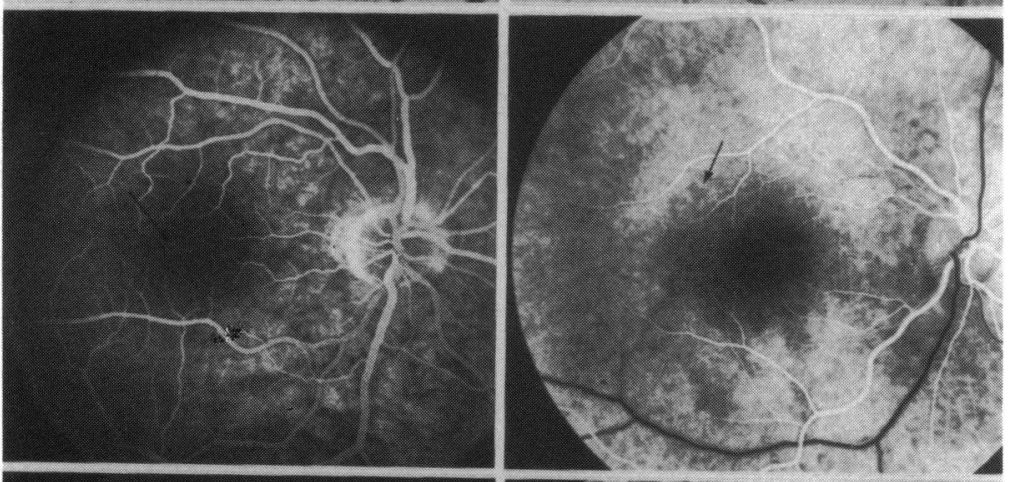
photography and fluorescein angiography. Left, patient $I V_{29}$ (age 28 years; visual acuity 20/30). The macular region of the right eye has a vitelliform lesion ophthalmoscopically (arrow) and a defect in the temporal nerve fibre bundle. The (arrow) early (middle) and (arrow) late (bottom)

fluorescein angiography confirm these abnormalities. Right, patient $I V_{45}$ (age 24 years; visual acuity 20/20). The periphery of the right eye has a depigmented area ophthalmoscopically (arrow). This
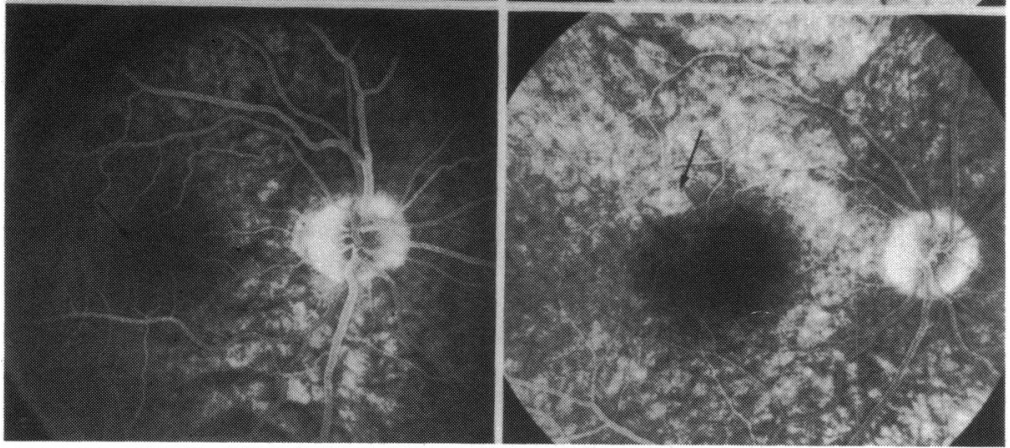
area demonstrates

hypofluorescence (arrow) early (middle) and hyperfluorescence (arrow) late (bottom). (Asterisk marks camera artefact.)

colour tests, and these tests were invariably positive only when visual loss was advanced. The electrooculogram was also inconsistent in this family, since even severe visual loss was not necessarily associated with an abnormal electro-oculogram. Thus this family, which meets all the criteria for autosomal dominance, represents the first instance of normal electro-oculograms in patients with a dystrophy similar to B-VMD.

It is estimated that in B-VMD only two-thirds of the genetically affected individuals have phenotypic expression consisting of visible macular changes and that in those with macular changes only $10 \%$ have vision $\leqslant 20 / 200$. ${ }^{9}$ This family with A-VMD is similar to that estimate, since in the 38 living affected persons in this pedigree only 9 eyes of 6 patients above the age of
14 years have vision of $\$ 20 / 200(12 \%)$. The other third of the genetically affected individuals with BVMD with no visible macular changes have been called 'carriers' and have been identified by their position in a family pedigree and/or by abnormally low electro-oculograms. These individuals are not really carriers, since they have the same genetic composition as the affected patients.

Accurate genetic counselling can be given only if individuals with the affected genotype can be recognised phenotypically. Further, linkage analysis can only be performed if disease status is correctly designated for all family members considered. In order to analyse the linkage data without prejudice it was felt necessary to have a consistent point to cease study of the patients both ophthalmologically and 
Fig. 7 Advanced central and peripheral retinal abnormalities in 2 affected family members demonstrated by fundus photography and fluorescein angiography. Top left, patient $I I_{12}$ (age 58 years; visual acuity 20/30). The macular area of the left eye has an advanced vitelliform lesion ophthalmoscopically and defects in the peripapillary region are extensive. Bottom left, the fluorescein angiograph demonstrates these lesions. Top right, patient $\mathrm{III}_{7}$ (age 48 years; visual acuity 20/20). The peripheral retina of the right eye has a large peripheral depigmented scar as well as several small yellow lesions similar to those seen in less advanced cases. Bottom right, the fluorescein angiograph demonstrates these lesions.
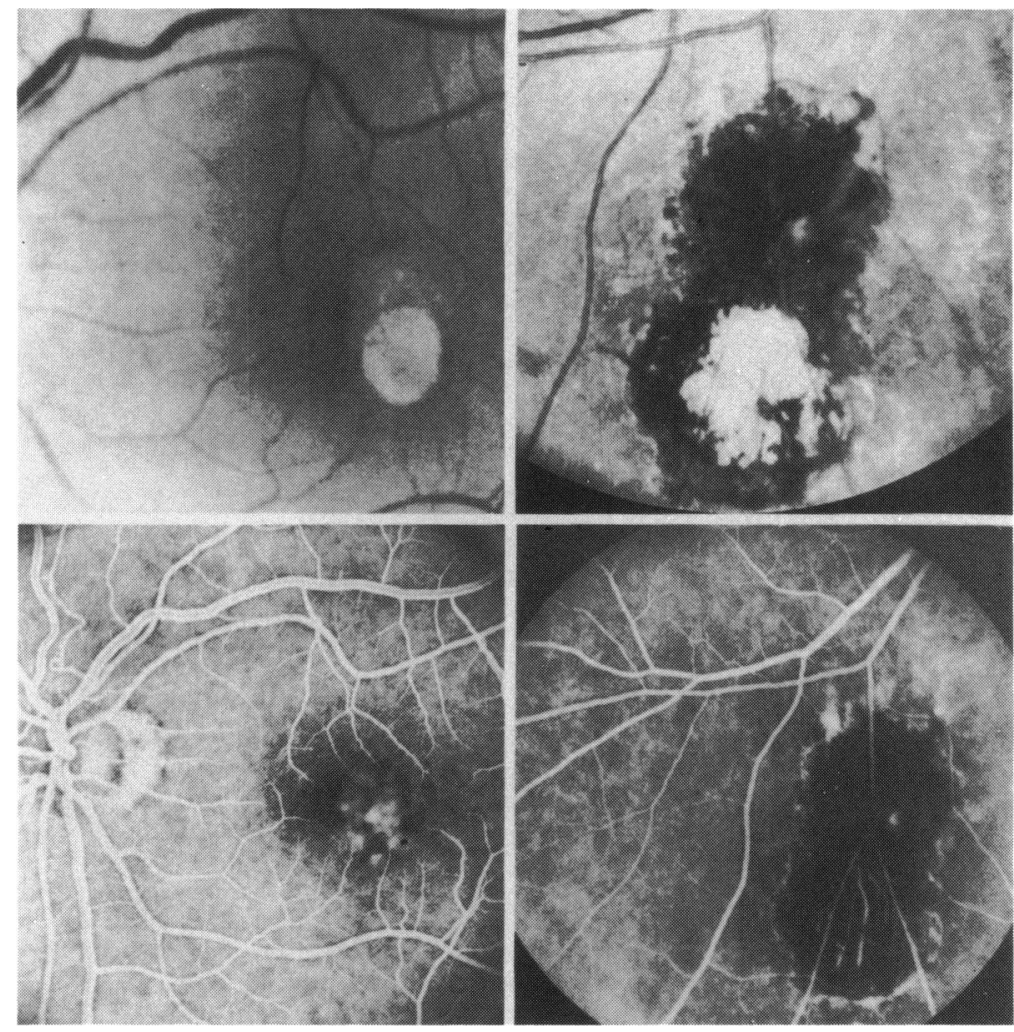

genetically. Fourteen years was selected because at the time of the initial study of 70 individuals in 1974 the youngest ophthalmologically affected patient was found to be 16 years old.

In 1981 an examination of 105 individuals identified the youngest ophthalmologically affected patient to be 14 years old, and a preliminary linkage study of blood samples obtained from these family members suggested linkage to the soluble glutamate pyruvate transaminase (GPT1) locus. It was felt desirable to confirm the linkage. Therefore, it was decided to study as many offspring of the doubly heterozygous family members (affected members with GPT1 type $2-1)$ as possible, since these individuals yield most of the information in a linkage analysis. ${ }^{20}$ For this reason, more examinations were performed in 1981 with special attention given to the offspring of the doubly heterozygous family members, including fluorescein angiography to confirm their disease status. During this study 23 additional examinations were performed, and their blood samples were also collected. This included all such potentially informative individuals except $I_{23}$ and $I V_{43}$. Selecting the age of 14 years as a consistent point to cease studying patients also virtually eliminated generation $\mathrm{V}$ without prejudice.
Variable expressivity has been well recognised as an obstacle to the establishment of linkage, and all methods available must be employed to demonstrate mild phenotypes who are nonetheless genotypically affected..$^{28-32}$ In this family, linkage between A-VMD and GPT1, thought to be on the short arm of chromosome 16, was established by means of maximum likelihood analysis $(\mathrm{Z}=4 \cdot 33$, that is, odds favouring linkage 22000 to 1 ). ${ }^{33}$

This study was supported in part by a grant from the Retina Research Foundation (Dr Hittner) and by EY-03430 from the National Institutes of Health (Dr Ferrell).

The authors acknowledge the help of Drs A. Linn Murphree, Richard A. Levacy, Paul K. Ayars, and Larry W. Arend, who as ophthalmology residents examined this family in 1974 and presented preliminary data on 9 of the affected family members at the Twelfth Annual Baylor Ophthalmology Alumni Meeting in April 1975 in Houston, Texas.

\section{References}

1 Barkman Y. A clinical study of a central tapetoretinal degeneration. Acta Ophthalmol (Kbh) 1961; 39: 663-71.

2 Deutman AF, Van Blommestein JDA, Henkes HE, Waardenburg PJ, Solleveld-Van Dreist E. Butterfly-shaped pigment dystrophy of the fovea. Arch Ophthalmol 1970; 83: 558-69.

3 Gass JDM. A clinicopathologic study of a peculiar foveomacular dystrophy. Trans Am Ophthalmol Soc 1974; 72: 139-56. 
4 Vine AK, Schatz H. Adult-onset foveomacular pigment epithelial dystrophy. Am J Ophthalmol 1980; 89: 680-91.

5 Gass, JDM. Drusen and disciform macular detachment and degeneration. Arch Ophthalmol 1973; 90: 206-17.

6 Gutman I, Walsh JB, Henkind P. Vitelliform macular dystrophy and butterfly-shaped epithelial dystrophy: a continuum? $\mathrm{Br} J$ Ophthalmol 1982; 66: 170-3.

7 Sabates R, Pruett RC, Hirose T. Pseudovitelliform macular degeneration. Retina 1982; 2: 197-205.

8 Borda RP. Clinical electro-oculography: optimum illumination levels for the light-adaptation phase. In: François J, DeRouck A, eds. Electrodiagnosis, toxic agents, and vision. Doc Ophthalmol Proc Ser. Boston: Junk, 1978: 15: 147-8.

9 Falls HF. The polymorphous manifestations of Best's disease (vitelliform eruptive disease of the retina). Trans Am Ophthalmol Soc 1969; 67: 265-82.

10 Maloney WF, Robertson DM, Duboff SM. Hereditary vitelliform macular degeneration. Arch Ophthalmol 1977; 95: 979-83.

11 Miller SA. Multifocal Best's vitelliform dystrophy. Arch Ophthalmol 1977; 95: 984-90.

12 Deutman AF. Electro-oculography in families with vitelliform dystrophy of the fovea. Arch Ophthalmol 1969; 81: 305-16.

13 Cross HE, Bard L. Electro-oculography in Best's macular dystrophy. Am J Ophthalmol 1974; 77: 46-50.

14 Bard LA, Cross HE. Genetic counselling of families with Best macular dystrophy. Trans Am Acad Ophthalmol Otolaryngol 1975; 79: 865-73.

15 Morse PH, MacLean AL. Fluorescein fundus studies in hereditary vitelliruptive macular degeneration. Am J Ophthalmol 1968; 66: 485-94.

16 Curry HF, Moorman LT. Fluorescein photography of vitelliform macular degeneration. Arch Ophthalmol 1968; 79: 705-9.

17 Miller SA. Fluorescence in Best's vitelliform dystrophy, lipofuscin, and fundus flavimaculatus. Br J Ophthalmol 1978; 62: 256-60.

18 Marmor MF. Dystrophies of the retinal pigment epithelium. In: Zinn KM, Marmor ME, eds. The retinal pigment epithelium. Cambridge: Harvard University Press, 1979; 424-53.

19 Deutman AF. Vitelliform dystrophy of the fovea. In: Deutman $\mathrm{AF}, \mathrm{ed}$. The hereditary dystrophies of the posterior pole of the eye. Springfield: Thomas, 1971; 198-299.
20 Krill AE. Vitelliruptive macular dystrophy. In: Krill AE, ed. Hereditary retinal and choroidal diseases. Hagerstown: Harper and Row, 1977; 665-704.

21 Kobrin JL, Apple DJ, Hart WB. Vitelliform dystrophy. In: Rabb MF, ed. Macular disease. International Ophthalmology Clinics, 21, No. 3. Boston: Little, Brown, 1981; 167-86.

22 Birndorf LA, Davison WW. A normal electro-oculogram in a patient with a typical vitelliform macular lesion. Invest Ophthalmol Visual Sci 1973; 12: 830-3.

23 Fishman GA, Trimble S, Rabb MF, Fishman M. Pseudovitelliform macular degeneration. Arch Ophthalmol 1977; 95: 73-6.

24 Kingham JD, Lochen GP. Vitelliform macular degeneration. Am J Ophthalmol 1977; 84: 526-31.

25 Marmor MF. 'Vitelliform' lesions in adults. Ann Ophthalmol 1979; 11: 1705-12.

26 Epstein GA, Rabb MF. Adult vitelliform macular degeneration: diagnosis and natural history. Br J Ophthalmol 1980; 64: 733-40.

27 Skalka HW. Vitelliform macular lesions. Br J Ophthalmol 1981; 65: $180-3$.

28 Hittner HM, Ferrell RE. Autosomal dominant ophthalmologic disorders and linkage. J Pediatr Ophthalmol 1982; 19: 40-6.

29 Hittner HM, Riccardi VM, Ferrell RE, Borda RP, Justice J. Variable expressivity in autosomal dominant aniridia by clinical, electrophysiologic, and angiographic criteria. Am J Ophthalmol 1980; 89: 531-9.

30 Ferrell RE, Chakravarti A, Hittner HM, Riccardi VM Autosomal dominant aniridia: probable linkage to acid phosphatase-1 locus on chromosome 2. Proc Natl Acad Sci USA 1980; 77: $1580-2$.

31 Hittner HM, Kretzer FL, Antoszyk JH, Ferrell RE, Mehta RS. Variable expressivity of autosomal dominant anterior segment mesenchymal dysgenesis in six generations. Am J Ophthalmol 1982; 93: 57-70.

32 Ferrell RE, Hittner HM, Kretzer FL, Antoszyk JH. Anterior segment mesenchymal dysgenesis: probable linkage to MNS blood group on chromosome 4. Am J Hum Genet 1982; 34: 245-9.

33 Ferrell RE, Hittner HM, Antoszyk JH. Linkage of atypical vitelliform macular dystrophy (VMD-1) to the soluble glutamate pyruvate transaminase (GPT1) locus. Am J Hum Genet 1983; 35: 78-84. 